\title{
Ivaldo Bertazzo: arte também é educação ${ }^{1}$
}

Em seus trinta anos de carreira, o premiado coreógrafo Ivaldo Bertazzo já trabalhou com uma infinidade de ritmos e danças. Na variedade de público que envolve seu trabalho, fundiu também conceitos de educaşão, psicologia e desenvolvimento corporal para mostrar que o corpo, por si só, é um dos mais eficientes canais de comunicação que o ser humano possui. Seu público privilegiado: cidadãos das mais variadas formações, além de jovens moradores de comunidades de baixa renda de São Paulo e do Rio de Janeiro. No depoimento a seguir, ele fala das descobertas de se trabalhar com educação e arte na formação de cidadãos.

Estudei em uma escola pública do Estado. Na minha época de estudante, elas eram rigorosas e boas. O mundo era menos rico, e havia mais intimidade entre as pessoas. Mas, mesmo com aulas de música no currículo - e é uma pena que não existam mais -, tive muita dificuldade na passagem do raciocínio para a criatividade. Mais tarde, vivi um período que me ajudou com relação a isso, no final da adolescência. De forma geral, as artes viviam uma época de muita criatividade. Existiam experiências artísticas menos vinculadas ao mercado de

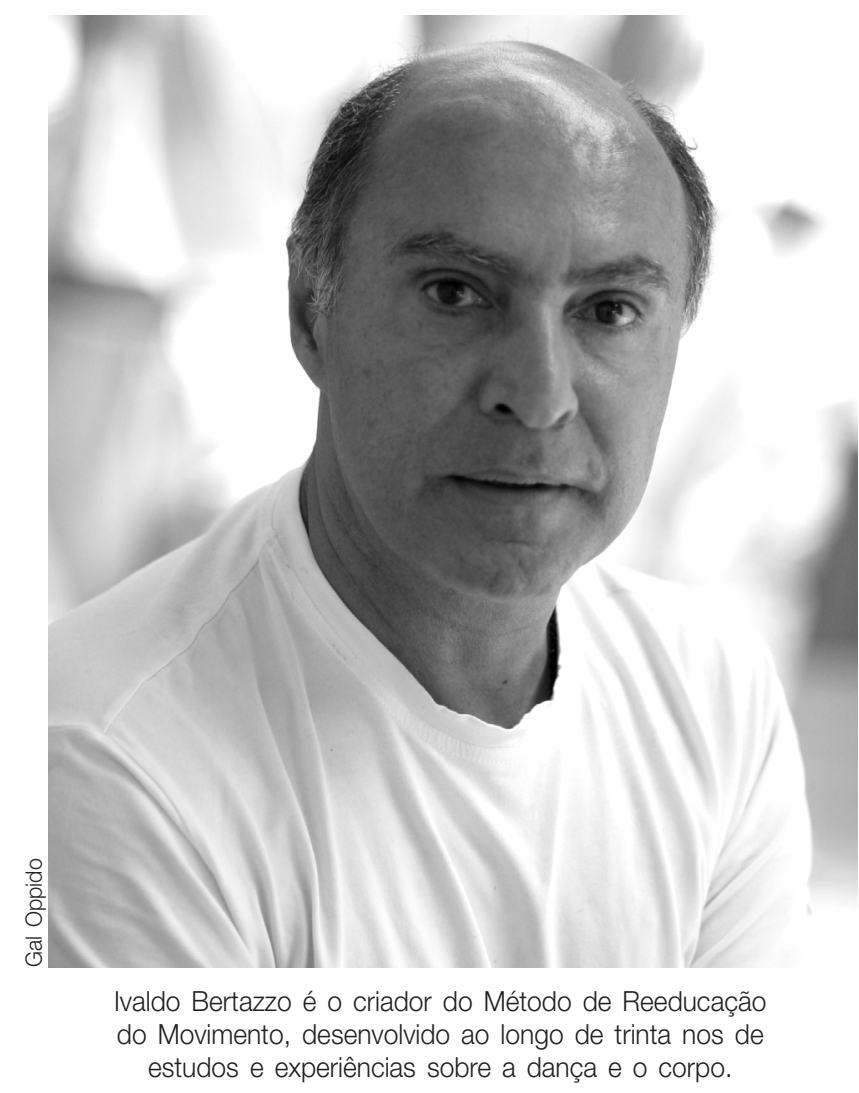
consumo. Isso me beneficiou muito. Aí eu tive uma grande escola. Depois, tardiamente, fui me especializar em áreas específicas, como fisioterapia, ensino de movimento, educação. Esse foi o meu percurso.

Acho que no início, durante a infância e a adolescência, o que realmente me estimulou foi estar em uma família muito voltada à música clássica. Em casa, existia esse universo que nos interiorizava. Mas a união entre sensibilidade e direção profissional, isso eu tive de achar. Essa, inclusive, é uma questão interessante. Como as famílias de classe média estão
1. Colaborou a jornalista Juliana Winkel. 
comunicação \& educação • Ano XI • Número 3 • set/dez 2006

induzindo o aspecto vocacional do seu jovem? A nossa sociedade é careta, mas essa caretice, que procura a eficiência profissional, não percebe que, se você acha a verdadeira vocação do seu filho, pode fazê-lo ser uma pessoa rica no futuro. Digo rica porque é isso que se almeja, infelizmente. Quando eu falei aos meus amigos, em 1974, "estou a fim de fazer dança", eles próprios se assustaram. "O que você vai ser no futuro?", diziam. Tive sorte. Vivi esse boom do trabalho corporal, tenho uma escola, alcancei o reconhecimento com meu trabalho. Muitos que fizeram Arquitetura, Direito, não tiveram o mesmo êxito. Será que eles realmente fizeram o que queriam fazer?

\section{INÍCIO DO TRABALHO COM A COMUNIDADE}

No início do meu trabalho, procurei desenvolver uma atividade fisioterápica pautada na respiração, por meio de referências bem definidas. Era simples e concreto. Hoje existem diferenças maiores entre os trabalhos, de ordem mais conceitual. Antigamente, tínhamos mais pesquisa no campo da dança, mas, em compensação, menos organização.

Mais tarde, na década de 1970, prestando atenção em performances artísticas não-profissionais, percebi que havia exposições de fotos, coral, teatro amador, porém eram muito raras as iniciativas envolvendo dança. Por quê? Era lógico: quando você vê um bailarino acadêmico, profissional, percebe que ele estruturou um corpo que ninguém consegue ter se não passar por muitos anos de treino. Entendi, então, que deveria desenvolver uma técnica de trabalho corporal que não fosse baseada na dança convencional. Nesse período, o Brasil estava vivendo a segunda metade da ditadura. Havia, na cena artística, uma evolução bastante intensa do trabalho corporal - porque era uma das possibilidades de ação. Foi uma forma de as pessoas realizarem ações individuais, já que no plano coletivo tudo era impedido. Começou a haver escolas de trabalhos corporais diferentes do que se conhecia. Hoje isso se reflete no aceleramento do trabalho corporal na academia. No início do trabalho, estávamos desenvolvendo o conceito de cidadão-dançante junto às classes B e C. Então, senti a necessidade de uma metodologia que não fosse baseada em dança contemporânea, à qual só tinham acesso os coreógrafos profissionais. As fontes para o desenvolvimento dessa nova metodologia foram países como Ásia, Índia, Indonésia. Neles, a expressão corporal privilegia o trabalho com as mãos, além de utilizar, de maneira muito clara, a geometria aplicada ao corpo - que traça triângulos, quadrados com a dança no espaço. A dança ocidental conhece esses conceitos, mas raramente os utiliza. Assim surgiu a idéia de unir as culturas ocidental e oriental. Tanto que o primeiro trabalho que produzimos com os cidadãos-dançantes foi um espetáculo sobre as culturas indiana e brasileira.

Em 1976, comecei a desenvolver essa nova metodologia por meio de um trabalho de performance de espetáculos com cidadãos, jornalistas, arquitetos, donas-de-casa, estudantes. Eram pessoas de perfil variado, que freqüentavam a minha escola. Para desenvolver esse trabalho, cercamo-nos de conhecedores de 
neurologia, anatomia e outros. Passamos então a analisar como o movimento, o gesto, vai construindo a nossa capacidade de intelecto. A partir daí, descobri um universo que me enlouqueceu. Percebemos que, para que as pessoas tenham algum índice de concentração, é necessário um mínimo de organização corporal, uma atitude postural que as levará a raciocinar. A espécie humana desenvolveu o intelecto por ter construído, ao longo de milênios, uma organização motora diferenciada. Ela diminuiu a massa na face e seu cérebro aumentou. Verticalizou-se e, com isso, adquiriu maior liberdade manual e maior desenvolvimento de raciocínio. E parece estranho, mas nós, em alguma etapa do nosso processo educacional, nos esquecemos disso. Veja, por exemplo, um adolescente sentado numa cadeira. Ele senta-se apoiado nas costas, com a cintura lá na frente. Com isso, bloqueia a coluna cervical e sua respiração torna-se bucal. Os olhos não têm foco, porque os braços estão muito soltos do eixo do corpo. Não existindo respiração nasal e uma suave organização vertical, ele não estrutura o foco de concentração para escutar.

Quando percebi isso, fiquei embasbacado. Vi que seria necessário trabalhar

coisas ainda mais básicas. É necessário desenvolver uma metodologia que também ajude a pessoa em seu trabalho intelectual. Entendo todas as preocupações que a escola, especialmente o ensino tradicional, tem com o armazenamento do conhecimento. Isso por si só já é uma tarefa monstruosa. Mas nós temos que nos preocupar um pouco ainda com a organização motora, porque, além de ser um preventivo à saúde, é um auxílio precioso ao raciocínio, à reflexão. Quais são as melhores condições para o ensino? As salas deveriam ser semi-esféricas, como um anfiteatro, onde o foco convergisse para o professor. Elas constantemente são retangulares. As cadeiras são extremamente desorganizadoras. Isso revela que nos esquecemos da organização motora e da psicomotricidade, que são capitais para se aumentar os índices de concentração. O mesmo acontece para todos, não só para o aluno. Se você entra numa grande empresa, as cadeiras são péssimas. Trabalhando num péssimo nível de organização, as pessoas até conseguem produzir, mas à custa de um estresse físico muito grande.

\section{COMUNIDADE E EDUCAÇÃO}

Começamos a trabalhar esses conceitos dentro do espetáculo Cidadão Dançante, ainda na década de 1970. Depois vieram outros espetáculos, até que percebi o aumento geral do interesse em trabalhar com a comunidade, por meio do desenvolvimento do Terceiro Setor. Entendi que o desafio maior era preparar o jovem da periferia. Porque o aluno de melhor condição econômica já usufrui ao menos de algum conhecimento, de algum tipo de informação.

Os jovens da periferia têm uma espontaneidade que transparece mais rápido. Normalmente possuem uma estrutura corporal mais sólida, pois se deslocam mais pela cidade em transportes coletivos. O jovem da elite costuma ser mais flácido e de pouca motivação para trabalhar com idéias abstratas. No dia-a-dia, desde cedo ele é exigido no sentido de produzir resultados, de se voltar a questões 
práticas na educação. O jovem da periferia se envolve mais facilmente com o trabalho artístico, mas, em compensação, dispõe de um repertório de valores culturais limitado. Ele não tem acesso a canais de TV a cabo, por exemplo, que mostram a arte de outros países. De forma geral, tanto o jovem de elite quanto da periferia precisam se libertar dos conceitos impostos pela mídia e pela religião. Então, a criação artística flui muito bem.

Comecei a levar meu trabalho para as comunidades periféricas. Foi um desafio, pois os jovens da periferia geralmente não têm muito contato com outras culturas, nem noções de diversidade cultural para entender que a expressão humana é muito variada. Esse jovem é ainda preso a um tipo específico de manifestação, de maneira de se vestir, de pensar. Quando se começa a abrir a visão deles para o conhecimento, percebe-se que eles mostram interesses muito peculiares. Digamos que $80 \%$ querem chegar à universidade, mas vão desistindo pelo meio do caminho, porque a universidade pública não existe na periferia. Sendo assim, passam a buscar o conhecimento técnico. E é uma pena que esse interesse, hoje, não encontre muitos caminhos para se desenvolver, porque atualmente há menos escolas técnicas do que antes. Se nem todos possuem vocação para o ensino universitário, devem existir outros caminhos. Tenho amigos com dinheiro que foram inteligentes para perceber que seus filhos se sairiam melhor como chefe de cozinha, como marceneiro, e os mandaram estudar fora do Brasil. Sabemos da ausência de bons técnicos para nos atender no cotidiano. Talvez devêssemos abrir opções nesses diferentes segmentos. Não podemos somente sonhar com o ensino universitário e esquecer esse outro lado.

É uma pena que a escola tenha de mostrar altos índices de competitividade para dizer que deu certo. Acho legítimo levar jovens da periferia para a universidade, essa ambição é boa. Assim como levar os filhos de classes mais privilegiadas para o aprendizado técnico, pois eles cursaram boas escolas e têm cultura - embora seja uma cultura entre aspas, pois muitas vezes não ouvem música, não têm o hábito da leitura.

A leitura é um problema geral. Hoje, $98 \%$ dos jovens de periferia só assistem a filmes traduzidos. Eles não lêem legendas. É preciso estimulá-los a isso, para acelerar a leitura e, depois, levá-los para o livro. O que eu estou falando é tão primário que muitas vezes nos esquecemos. Existe um fenômeno neuromotor surpreendente: quando você pede a esse jovem para escrever, ele escreve errado, mas comunica o que quer dizer. Se você pede para que ele diga aquilo verbalmente, ele tem má organização bucal, má oclusão, respira mal. Incrivelmente, apesar de escrever errado, ainda escreve melhor do que fala, no sentido de comunicar uma idéia. Melhorar isso é a minha tarefa.

Quem sabe o mais importante, então, seja ensinar o jovem a estudar. A primeira etapa na educação é falar e escrever bem. Depois, ter níveis de informação razoáveis. A partir daí, não importa se ele escolhe o ensino técnico ou universitário. Penso que o trabalho que desenvolvo é assim: não importa se ele vai se transformar ou não em bailarino ou músico. O principal é que ele, nesse processo, aprenda a se concentrar e a entender o que é um trabalho em equipe. 
É difícil em qualquer nível conseguir uma equipe que raciocine em conjunto, e depois fazer com que cada um vá para seu segmento e produza, voltando em seguida para o coletivo, e assim por diante. Nós mesmos, por meio de um grupo de pesquisa muito abrangente, envolvendo psicólogos, fisioterapeutas, procuramos estar atentos, no trabalho, às questões de saúde contemporânea. A atualização mais eficiente vem por meio do trabalho coletivo.

\section{APRENDER É COMUNICAR}

Faço parte de uma época, na década de 1970, do grande sonho do ensino integrado, em que se buscava novas atitudes de ensino que levariam a pessoa a encontrar a sua vocação. Nesse período, pensávamos em usar linguagens artísticas, porque a arte não é uma coisa separada da educação. É um processo de aprendizado muito preciso. Queríamos levá-la para o ensino e criar integração. Isso não aconteceu a contento. Hoje em dia, as melhores escolas oferecem dança, teatro, fora do currículo. A idéia original era usar o teatro associado ao professor de português, a música associada ao professor de matemática. Usar o gesto, a dança, e não somente o esporte - que cumpre sua função, mas é li-

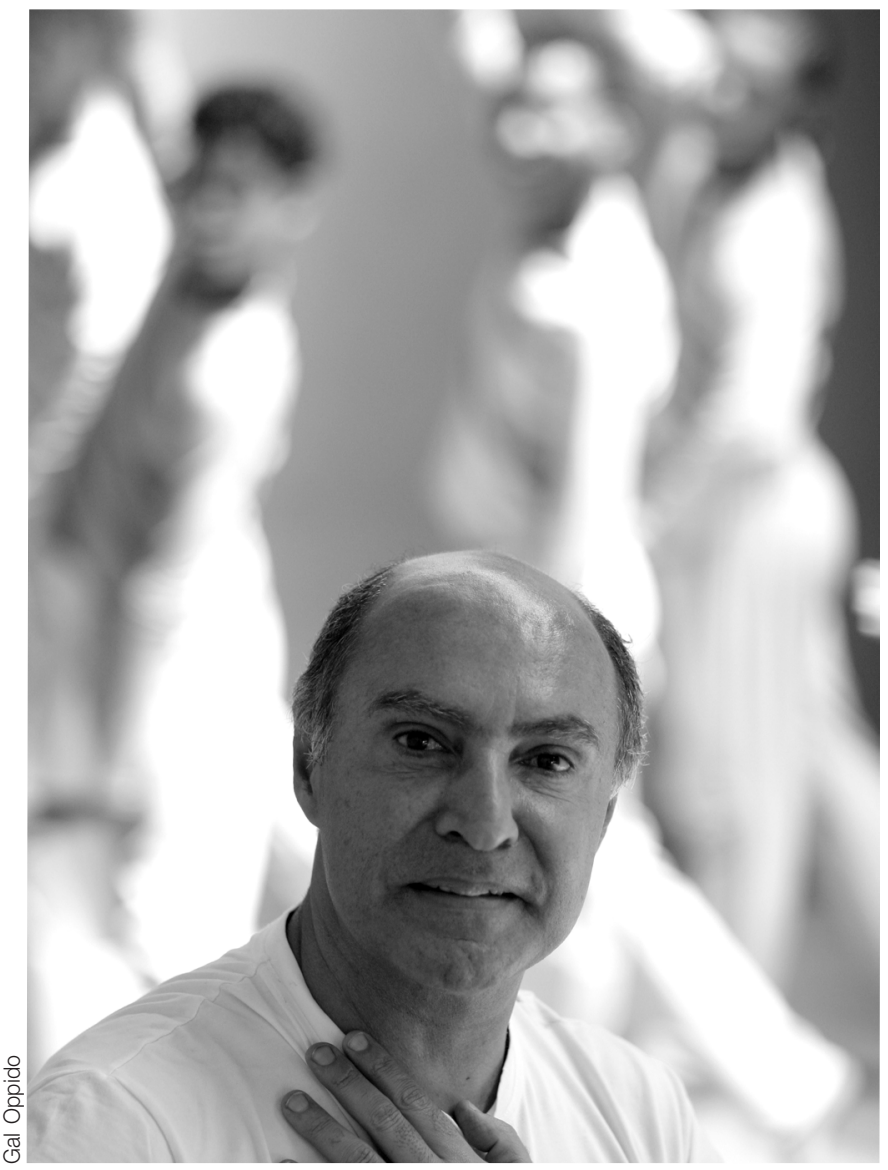

Os projetos com as comunidades da periferia foram concebidos com o intuito de capacitar os jovens para o mercado de trabalho e para o exercício da cidadania. mitado por ser extremamente competitivo. Ele não interioriza suficientemente a criança. Ou seja, numa época de avançada tecnologia da comunicação, não ensinam à criança que seu próprio corpo é uma ferramenta de comunicação. Quando ela não se organiza corporalmente, não consegue também se organizar para fazer seu discurso.

Hoje, quando você pede a um jovem para ler um parágrafo e dizer o que entendeu, o processo para ele se comunicar é muito complexo. E é através do gesto, da música, do teatro, que se pode conduzi-lo a essa organização. Infelizmente não vemos, na escola, 
comunicação \& educação • Ano XI • Número 3 • set/dez 2006

esse processo. Os educadores têm de correr tanto com a transmissão de conteúdo para fazer o aluno entrar na universidade, ou para chegar a uma empresa e competir no mercado de trabalho, que acabam se esquecendo disso. Então, meu trabalho é chegar ao jovem da periferia e ensinar-lhe uma série de coisas às quais não tem acesso, para que, voltando ao seu bairro e à sua rua, infiltre isso no seu street dance, no seu teatro, até mesmo na construção de texto e de poesia. Acho que uma saída, nesse processo, é formar professores - para que cada aluno possa ter um emprego no seu bairro como professor de música, de dança, de teatro. Mas com qualidade.

Esse profissional demora cerca de um ano e meio para preparar-se. Não pode ser por cursos rápidos. Uma coisa é a ONG receber 2.500 jovens para tocar música e fazer teatro. Isso é ocupação de lazer. Outra coisa são ensinamentos mais aprofundados nesse setor. $\mathrm{O}$ foco desse aprendizado, na primeira etapa, não é o prazer. A primeira etapa é difícil; normalmente o jovem fica irritado. Sendo assim, propomos que recebam uma ajuda de custo. Não só porque o jovem quer o dinheiro, mas porque esse dinheiro o deixa mais tranqüilo para aprender. A fim de que esse aprendizado seja satisfatório, ele não pode se dedicar menos do que duas horas por dia, cinco vezes por semana. É um compromisso muito ambicioso. Seria utópico? Se as empresas têm o desejo de desenvolvimento neste país e não investem na qualidade desses jovens, qual será o trabalho futuro nessa empresa? Quando algum empresário diz que o seu boy fica louco para sair mais cedo porque quer ensaiar na banda, ele tem de deixar. A banda vai ajudar esse rapaz a deixar de ser boy e passar a ser auxiliar de escritório daqui a um ano. Isso se nós, lá na banda, introduzirmos outros valores.

\section{O CAMINHO DA INCLUSÃO}

O ensino público tenta, sim, dar seus passos na direção da ampliação do conhecimento. Cabe a nós, também, procurar parcerias para ajudar o ensino público, em vez de censurá-lo. O trabalho que desenvolvo deveria ser associado à escola. Temos de perguntar a ela: "Do que você não está dando conta? Deixa que eu resolvo isso aqui no teatro". Percebo que o diretor da escola ainda não entende muito bem o trabalho de arte-educação. Mas a tarefa não é dele. Nós é que precisamos ir a ele, fazer um programa-piloto para que ele desenvolva e entenda que o jovem senta torto, respira mal, tem encurtamentos musculares muito maiores do que anos atrás. Esses encurtamentos são gravíssimos. Ele não consegue ficar sentado por muito tempo. É impressionante como, em relação à saúde, ainda não enxergamos os problemas que virão.

Essa é a estratégia pela qual estou lutando no momento. A inclusão do jovem na sociedade é conseguir que ele chegue ao mercado de trabalho. Não é aplauso. Aplauso é prazer. A inclusão é fazer com que, quando ele for para uma empresa, não tenha medo de dizer: "Eu sou da periferia". Mas tem de dizer isso numa boa postura e numa linguagem do lado de cá - porque existem duas linguagens. Precisamos conhecê-las, não para modificá-las, mas para 
aprender com elas. Não existem famílias que falam alemão dentro de casa e na rua, português? Esse jovem precisa falar a linguagem da periferia e, aqui, a nossa linguagem, senão ele não se inclui. Por isso, quando se ensina dança, a língua portuguesa é capital. Você não pode ensinar dança, música, e não ensiná-lo a falar. Essa é a essência do trabalho educativo.

Para os educadores, faz sentido. Mas, muitas vezes, existe uma parede de incompreensão de como estabelecer esse elo. Quando as ONGs começaram a trabalhar na periferia, quiseram atrair os jovens para incluí-los em algum processo. Primeiro criaram-se cursos de informática, inglês, cursinhos pré-vestibulares. Acho legítima essa iniciativa, mas quando o jovem sai dali, são restritos os subsídios que a ONG conseguirá, diante da demanda, para que ele entre na faculdade. Então, incorporaram-se teatro, música, canto, dança a fim de despertar o interesse no jovem. Isso criou o boom do bate-lata que houve nos últimos doze, treze anos. Intuitivamente se percebeu que dava certo, porque o foco eram as mãos que se juntam para bater no tambor. Assim se criam estruturas rítmicas que se repetem. Quando uma estrutura é construída no cérebro, ele abre espaço para outra mais complexa. Portanto, pode-se tentar evoluções rítmicas como a que já tentei na Maré, no Rio de Janeiro. Dançávamos Stravinsky, que tem uma construção rítmica assimétrica, bem complexa. Envolve raciocínio. Precisamos sair da estrutura simétrica, monocórdia, como são o funk e o axé-music.

\section{DA TEORIA À PRÁTICA}

Percebi que, se o atrativo era uma atitude performática no bate-lata, no teatro, na dança, tínhamos de refinar o conhecimento do arte-educador da periferia para que ele usasse isso como estratégia, a fim de ampliar o desejo do jovem de aprender. O aprendizado é um vírus que você precisa pôr dentro do jovem. Você necessita abrir processos internos e fazê-lo querer aprender mais.

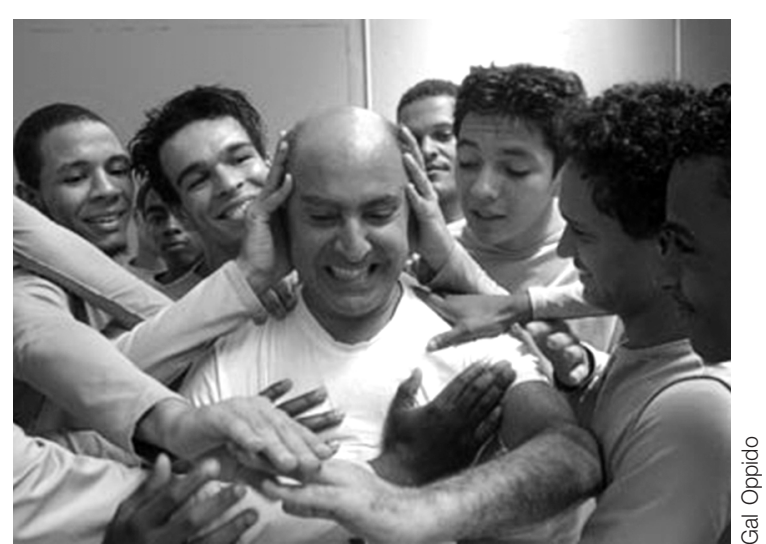

Samwaad - rua do encontro, resultado de oito meses de ensaio com 54 jovens de sete ONGs paulistanas.

Esse jovem é estigmatizado porque a mídia o fecha lá, na periferia, colocando-o num padrão muito interessante para ela - porque eles são grandes consumidores. Todos têm celular, têm bons tênis. Falo do jovem da periferia que não está comprometido com o tráfico. Neste caso, seria outro trabalho, de tirar o jovem do tráfico. Na ONG eles já identificam os jovens questionadores, que se interessam. Aí fazemos testes de psicomotricidade, vemos como eles se organizam nesse sentido: foco de olhar, organização das mãos, da escrita. Isso é muito importante, porque senão eles vão sofrer muito durante o trabalho e 
irão se sentir inferiores aos que têm índice motor melhor. Índice motor não é apresentar um corpo de bailarino clássico, mas diz respeito aos índices de raciocínio: tocar uma estrutura musical e ver se ele entende, se tem agilidade de raciocínio. Percebemos na hora. Assim vamos melhorando a qualidade.

Precisei passar por uma experiência desde o palco, seguindo pela academia e pela periferia, a partir de um espetáculo que fiz em 1994 no Sesc-Pompéia. Foi um período muito longo até começar a ver os acertos e desacertos da metodologia. Agora, já existem jovens dentro desse grupo que estão prontos para trabalhar com essa metodologia na periferia, depois de um bom tempo de experimentação para ver quais atalhos aceleravam o processo de organização motora e de raciocínio. Tenho visitado institutos e fundações, dizendo: "Nós temos esse programa, vamos implantá-lo?”. Nosso objetivo não é introduzir isso no sistema de ensino, porque, infelizmente, não há tempo no currículo. Tem de ser na hora do lazer, que no geral é mal-aproveitada, não importa em que classe social.

Ver os jovens se interessando pelo teatro porque querem ganhar na loteria, trabalhar em novelas na televisão, me dá um profundo desgosto, pois não estão pensando na vocação. Hoje não se estimula mais a vocação. Para esse jovem que me procura querendo fazer teatro, digo: "Vá primeiro saber qual é o seu desejo. Porque o seu desejo, agora, é ganhar na loteria. Isso é outra coisa”. A vocação é um instinto, um cheiro que te leva numa direção. A vocação estava nos jovens, dos quais eu fiz parte, que ficavam loucos na porta de um teatro porque não tinham dinheiro para entrar, insistindo até que alguém os pusesse para dentro. Isso exigia um esforço absoluto, mas era muito gratificante passar por essa dificuldade e conseguir assistir a um espetáculo. Vocação é ir atrás.

Resumo: O premiado coreógrafo Ivaldo Bertazzo já trabalhou com uma infinidade de ritmos e danças em seus trinta anos de carreira. Neste depoimento, fala das descobertas de se trabalhar com educação e arte na formação de cidadãos; conta como é lidar com a variedade de público que envolve seu trabalho e como fundiu também conceitos de educação, psicologia e desenvolvimento corporal para mostrar que o corpo, por si só, é um dos mais eficientes canais de comunicação que o ser humano possui. Seu público é privilegiado: cidadãos das mais variadas formações, além de jovens moradores de comunidades de baixa renda de São Paulo e do Rio de Janeiro.

Palavras-chave: dança, desenvolvimento corporal, arte-educação, teatro, cidadão dançante.
Abstract: In his thirty years of career, the awarded choreographer Ivaldo Bertazzo has already worked with a variety of rhythms and dances. In this testimony, he describes his experience on how to unite education and art to stimulate citizenship. Among several aspects involved in his work, Bertazzo tells the reader how he has instilled concepts of education, psychology and corporal development to show that body, by itself, is one of the most efficient communication channels the human being has. His students are very diversified: he works with citizens of various ages, and levels of formal education, but especially with youngsters living in low income communities in São Paulo and Rio de Janeiro.

Keywords: dance, corporal development, art-education, theater, dancing citizen. 